\title{
COMPARAÇÃO DA TÉCNICA TRADICIONAL E DO MÉTODO TURBIDIMÉTRICO AUTOMATIZADO NO CULTIVO EM DIFERENTES FONTES DE CARBONO DE FUNGOS FILAMENTOSOS ISOLADOS DE SOLO DE ÁREA DE CAATINGA
}

COMPARISON OF THE TRADITIONAL TECHNIQUE AND AUTOMATIZED TURBIDIMETRIC METHOD IN THE CULTIVATION IN DIFFERENT CARBON SOURCES OF FILAMENTOUS FUNGI ISOLATED OF SOIL IN CAATINGA AREA

\section{Simões, M. L. G. ${ }^{1,2,3}$; Tauk-Tornisielo, S. M. ${ }^{1}$}

${ }^{1}$ Universidade Estadual Paulista (UNESP), Centro de Estudos Ambientais - Avenida 24-A, 1515, Bairro Bela Vista. CEP13506-900, Rio Claro, SP, Brasil

${ }^{2}$ Avenida Paulo Filadelfo, 18, Candeias, Cep. 45050-020, Vitória da Conquista, BA, e-mail: marialuciags@ig.com.br

\section{RESUMO}

Os fungos filamentosos constituem, atualmente, materiais biológicos ideais para produção de substâncias de interesse biotecnológico, pois são de crescimento rápido, baixo custo de cultivo, possibilitando cultivos sob condições controladas em laboratório. Existe, entretanto, grande número de variáveis que afeta a produção de compostos pelos fungos, dentre elas destaca-se a composição do meio de cultura utilizado. Este trabalho se propõe avaliar o efeito de diversas fontes de carbono no crescimento de duas linhagens de fungos filamentosos Aspergillus niger e Rhizopus microsporus isoladas do solo de área de caatinga, mediante dois métodos, o de crescimento por parâmetros automatizados de turbidimetria, sob condições de agitação e temperatura controladas, e pelo método tradicional, em Erlenmeyers, nas mesmas condições, com o objetivo de se atestar à qualidade e segurança dos resultados do método automatizado, que se propõe ser uma via de trabalho mais barata e rápida.

Palavras-chave: Caatinga, Aspergillus niger, Rhizopus microsporus, fontes de carbono, biomassa. 


\begin{abstract}
Filamentous fungi are today, ideal biological material to produce substance of biotechnological interest, because their fast growth, low cultivation cost, allowing to be cultivated under laboratory controlled conditions. There are, however; a great number of variable that affect the production of composed produced by the fungi and among them, the culture medium used stands out. The aim of this research was to evaluate the different carbon sources of two strains of filamentous fungi Aspergillus niger and Rhizopus microsporus, isolated of soil in caatinga area, through two methods, the growth by automatized turbidimetric parameters, and under agitated, and temperature controlled conditions, and by traditional methods in Erlenmeyers, under the same conditions with the aim to certificate the assurance of the results by the automatized method, which is up to be a cheap and fast way of work

Key words: Caatinga, Aspergillus niger, Rhizopus microsporus, Bioscreen, carbon sources, biomass.
\end{abstract}

\title{
1. INTRODUÇÃO
}

Este estudo tem como objetivo considerar a importância do conhecimento do potencial biotecnológico dos fungos encontrados no solo, principalmente de ecossistemas que estão sendo gradativamente destruídos, tais como a caatinga. Esta se encontra com um acelerado processo de desertificação, ocasionado, principalmente, pelo desmatamento e uso inadequados de seus recursos naturais. A caatinga é a vegetação predominante da região semi-árida do Brasil, totalizando $11 \%$ do território nacional e é um bioma único no mundo (DRUMOND et al., 2000).

De longa data, os fungos filamentosos têm sido utilizados em processos fermentativos nas industrias de alimentos e farmacêuticas, na agricultura e na descontaminação de ambientes aquáticos e terrestres, entre outros, através de enzimas e ácidos orgânicos por eles produzidos (BONONI, 1999).Os fungos são de crescimento rápido e baixo custo de cultivo, o que possibilita uma analise do seu potencial biotecnológico de forma mais rápida, sendo que vários métodos têm sido descritos para otimização dos meios de cultivo utilizados para este fim (BOCHINI, 2000).

A busca de substâncias produzidas por microrganismos como fontes alternativas para uso nos diversos setores industriais, tem proporcionado a descoberta de que os fungos constituem materiais biológicos ideais para este fim. Isto se deve ao fato de apresentar diversidade morfológica e fisiológica típica, por terem importante papel onde se encontram na natureza e por representarem vastas possibilidades de aplicações em biotecnologia (RUEGGER et al., 2001).

A glicose é uma das fontes de carbono mais adequada praticamente para todos os bolores, mas outros açúcares podem ser utilizados, como a sacarose, lactose, maltose, assim como também compostos orgânicos mais complexos (PELCZAR et al., 
1996). Existe, portanto, um grande número de variáveis que afetam a produção de compostos por fungos, dentre elas destaca-se a composição do meio de cultura utilizado (SKOWRONEK e FIEDUREK, 2004).

Um teste rápido, mas detalhado pode ser desenvolvido em Bioscreen $\mathrm{C}$ (um sistema automatizado de crescimento microbiano, adquirido de Labsystems $\mathrm{Ou}$, Helsinki, Finlândia). Este equipamento tem sido usado para muitas aplicações em microbiologia, incluindo pesquisas gerais (ALVAREZ-BARRIENTOS et al., 2000), em efeitos de compostos químicos no crescimento de microrganismos (LISOWSKA et al., 2004), em qualidade de controle (MATTILA et al., 1988; JOHNSTON, 1998) e outras aplicações. O "software" converte cineticamente medidas da absorbância em curvas de crescimento e constrói gráficos com calibrações adequadas. As placas e amostras são esterilizadas e podem ser utilizadas 200 amostras por teste, possibilitando replicações adequadas.

\section{MATERIAL E MÉTODOS}

\subsection{Microrganismos}

A coleta de material foi realizada no final do período chuvoso de março, de solos de área de caatinga, na Floresta Nacional Contendas do Sincorá, localizada na micro-região dentro da homogênea Chapada Diamantina Meridional, município de Ituaçú, estado da Bahia, Brasil. Entre as espécies isoladas, duas foram identificadas no Instituto Botânico-SP, pela professora doutora Iracema S. Crusius, sendo Aspergillus niger e Rhizopus microsporus var. microsporus van Tieghen .

\subsection{Bioscreen $\mathrm{C}$}

O aparelho consiste de um espectrofotômetro contendo duas placas estéreis, cada uma contendo 100 células de cultivo, onde os microcultivos são realizados, produzindo turbidez proporcional ao crescimento celular no meio de cultura. $\mathrm{O}$ aparelho permite que sejam pré-determinados os parâmetros cinéticos que se deseja no experimento: comprimento de onda para leitura das densidades ópticas (OD), tempo de cultivo, temperatura, tipo e freqüência de agitação e freqüência das leituras de absorbância das células. O software converte automaticamente as medidas da absorbância em curvas de crescimento que são analisadas em um computador acoplado.

\subsection{Preparação dos Inóculos}

Adicionou-se solução Tween 80 ( $\mathrm{T}$ 80) $0,1 \%$ aos tubos de cultura, cobrindo a superfície do cultivo, que foi suavemente raspada com um estilete estéril. A solução foi filtrada e recolhida em Becker de $125 \mathrm{~mL}$ esterilizado. Com auxílio de microtúbulos assépticos, uma gota do filtrado foi colocada em câmara de Neubauer e levada ao microscópio óptico para contagem dos esporos. A solução, se necessário, foi 
ajustada de modo que a contagem de esporos ficasse próxima a $1 \times 10^{7}$ esporos $/ \mathrm{mL}$, concentrando-a com mais inoculo ou diluindo-a com solução T80.

\subsection{Preparação das Placas de Microcultivo para Leituras das Absorbâncias Automatizadas}

O meio de cultura utilizado foi extrato de levedura liquido $1 \%$, distribuído em vidros de penicilina e acrescidos individualmente com as seguintes fontes de carbono 1\%: lactose, sacarose, maltose, glicose, glicerol, sorbitol, frutose, xilose e galactose. Os vidros foram selados, etiquetados e esterilizados em autoclave a $121^{\circ} \mathrm{C}$ por 20 minutos, $1 \mathrm{~atm}$, como os demais materiais utilizados no processo. Cada linhagem foi analisada em quintuplicadas para cada uma das nove fontes de carbono estudadas, sendo que os controles de cada meio de cultura fonte realizados em triplicata. Para os controles foram adicionados $400 \mu \mathrm{L}$ de cada fonte de carbono $1 \%$. Nas células onde se avaliou o crescimento dos fungos, adicionaram-se $360 \mu \mathrm{L}$ da fonte de carbono $1 \%$, acrescidos de $40 \mu \mathrm{L}$ da solução de esporos $1 \times 10^{7}$ esporos $/ \mathrm{mL}$. O aparelho (Bioscreen C) foi calibrado para que operasse segundo os seguintes parâmetros: temperatura $35^{\circ} \mathrm{C}$, absorbância $540 \mathrm{~nm}$, intervalo entre leituras de 4 horas, tempo total do experimento de 60 horas, agitação média das células, efetuada 10 segundos antes de cada leitura. As leituras automáticas foram analisadas por computador acoplado, no qual os resultados foram obtidos após as 60 horas, sendo então determinadas curvas de crescimento das linhagens de fungos nas referidas fontes de carbono.

\subsection{Cultivos de Fungos Filamentosos em Meios de Cultura Líquidos pelo Método Tradicional com Frascos Agitados}

As mesmas linhagens utilizadas no cultivo automatizado, foram cultivadas em triplicata em frascos Erlenmeyers de $125 \mathrm{~mL}$, contendo $50 \mathrm{~mL}$ de extrato de levedura $1 \%$, suplementados com fontes de carbono a $1 \%$ e $5,0 \mathrm{~mL}$ de solução de esporos na concentração $1 \times 10^{7}$ esporos $/ \mathrm{mL}$, mantendo-se as mesmas proporções utilizadas anteriormente. Os frascos permaneceram sob agitação a $150 \mathrm{rpm}$, a $35^{\circ} \mathrm{C}$, por cinco dias.As biomassas das linhagens foram separadas através de filtração a vácuo em papeis de filtro Whatman $\mathrm{n}^{\circ} 1$, e colocadas em estufa a $80^{\circ} \mathrm{C}$ até obtenção do peso constante, determinado gravimetricamente em balança analítica.

\section{RESULTADOS E DISCUSSÃO}

As curvas de crescimento obtidas através do método turbidimétrico automatizado dos diferentes cultivos com Aspergillus niger se encontram na Figura 1, podendo ser observado que as melhores fontes de carbono para o crescimento desta linhagem, em ordem decrescente, foram: maltose, sacarose, galactose, glicose, frutose, xilose, glicerol, lactose e sorbitol. Na Figura 2 estão as curvas de crescimento obtidas nos cultivos da linhagem de Rhizopus microsporus, verificando-se respostas distintas quanto ao crescimento desta em diferentes fontes de carbono em relação à anterior, em 
ordem decrescente têm-se: glicerol, xilose, frutose, maltose, sacarose, lactose, sorbitol, galactose e glicose.

As Figuras 3 e 4 mostram as curvas obtidas a partir dos cultivos das duas linhagens através do método tradicional em frascos agitados. A linhagem de Aspergillus niger apresentou maior quantidade de biomassa em meio de cultura contendo maltose, como única fonte de carbono e a linhagem de Rhizopus microsporus, em meio contendo glicerol, concordando com os resultados obtidos no sistema automatizado.

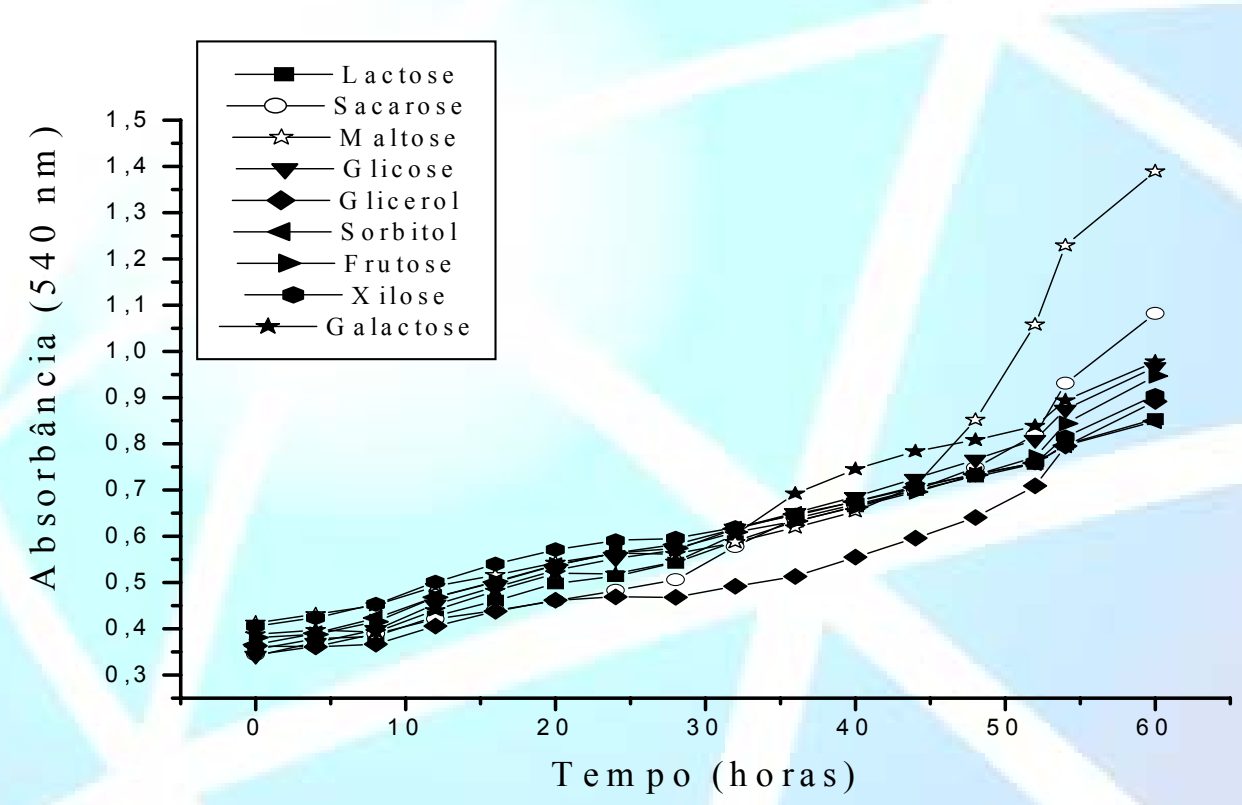

Figura 1- Curvas de crescimento de Aspergillus niger com diferentes fontes de carbono em cultivo automatizado (Bioscreen $\mathrm{C}$ ). 


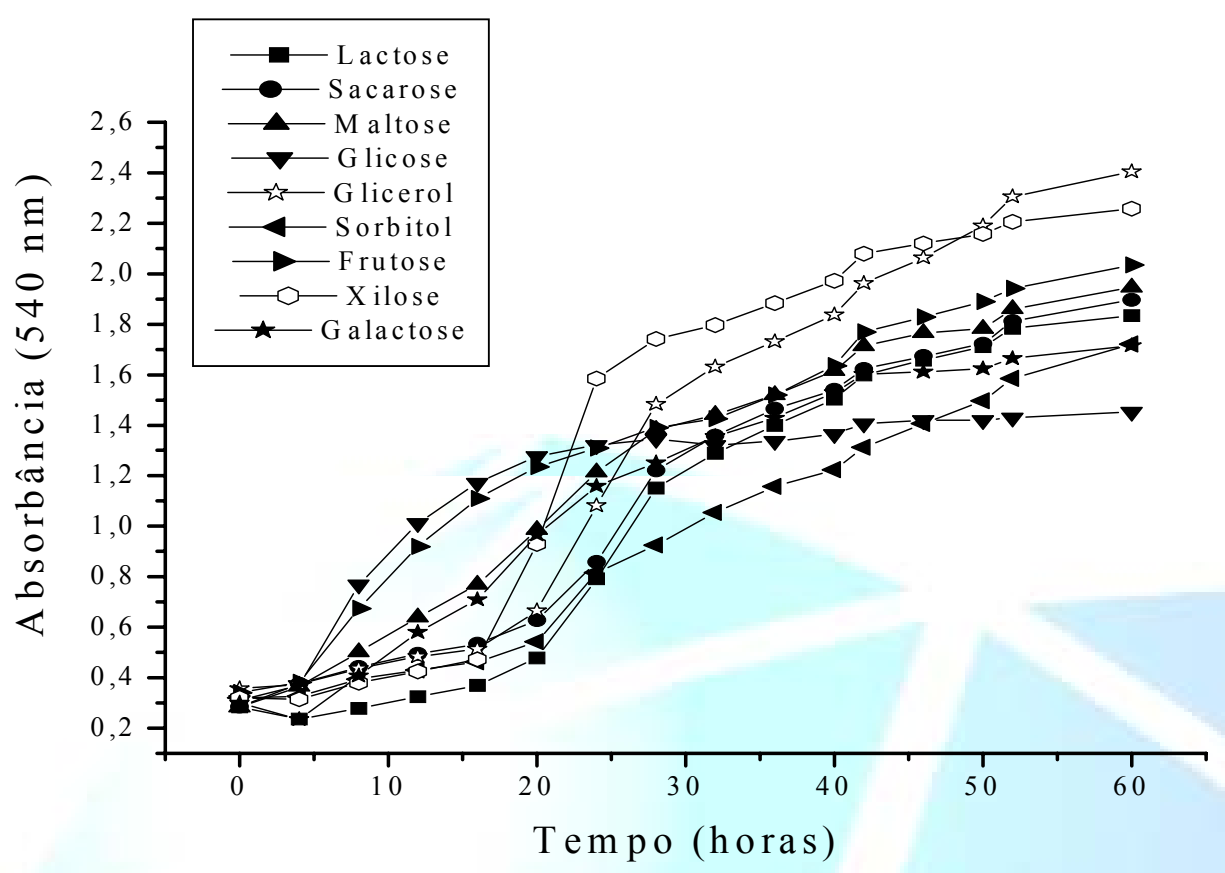

Figura 2- Curvas de crescimento de Rhizopus microsporus com diferentes fontes de carbono em cultivo automatizado (Bioscreen C).

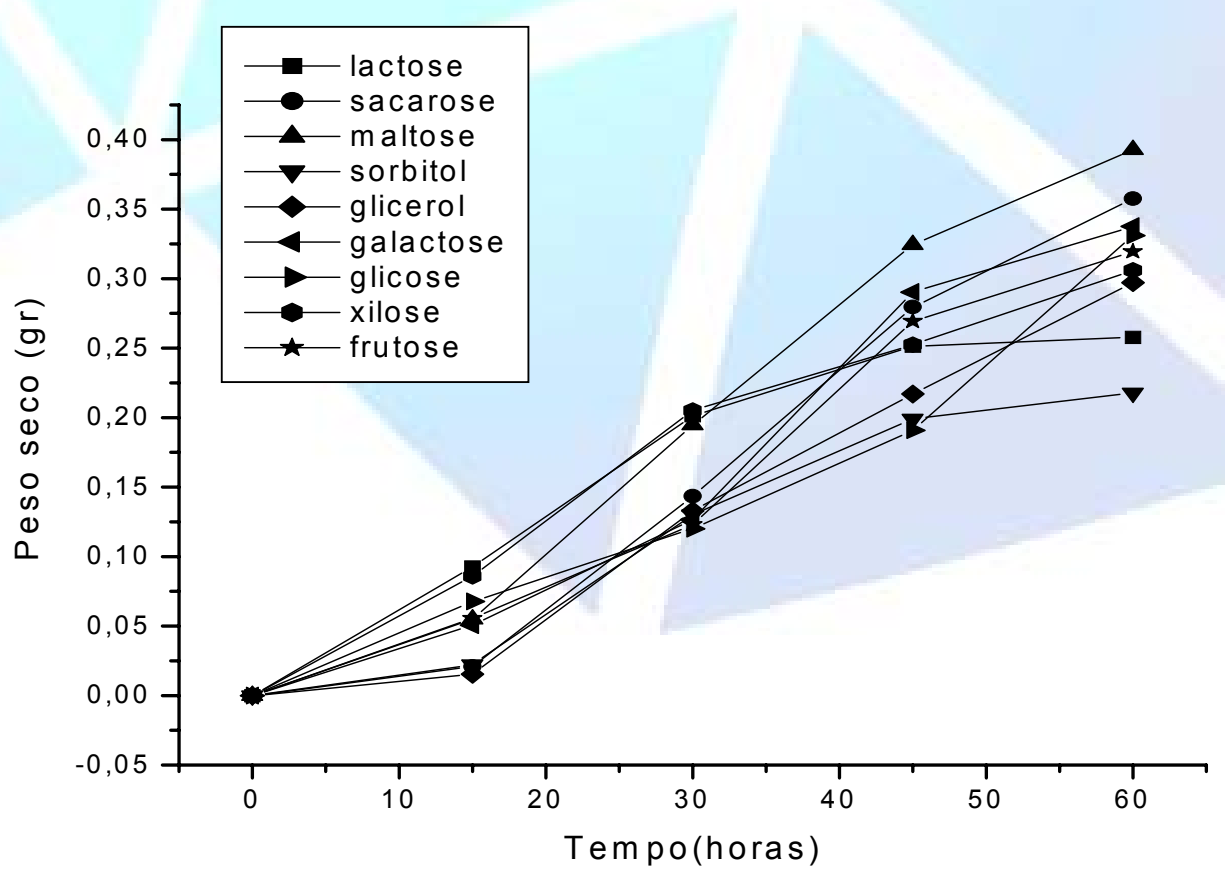

Figura 3- Curva de crescimento de Aspergillus niger com diferentes fontes de carbono por método tradicional. 


\begin{tabular}{|l|r|}
\hline Recebido em: $17 / 03 / 2005$ & HOLOS Environment, v.5 n.2, 2005 - P.100 \\
\hline Liberado para Publicação em: $23 / 01 / 2006$ & ISSN: 1519-8634 \\
\hline
\end{tabular}

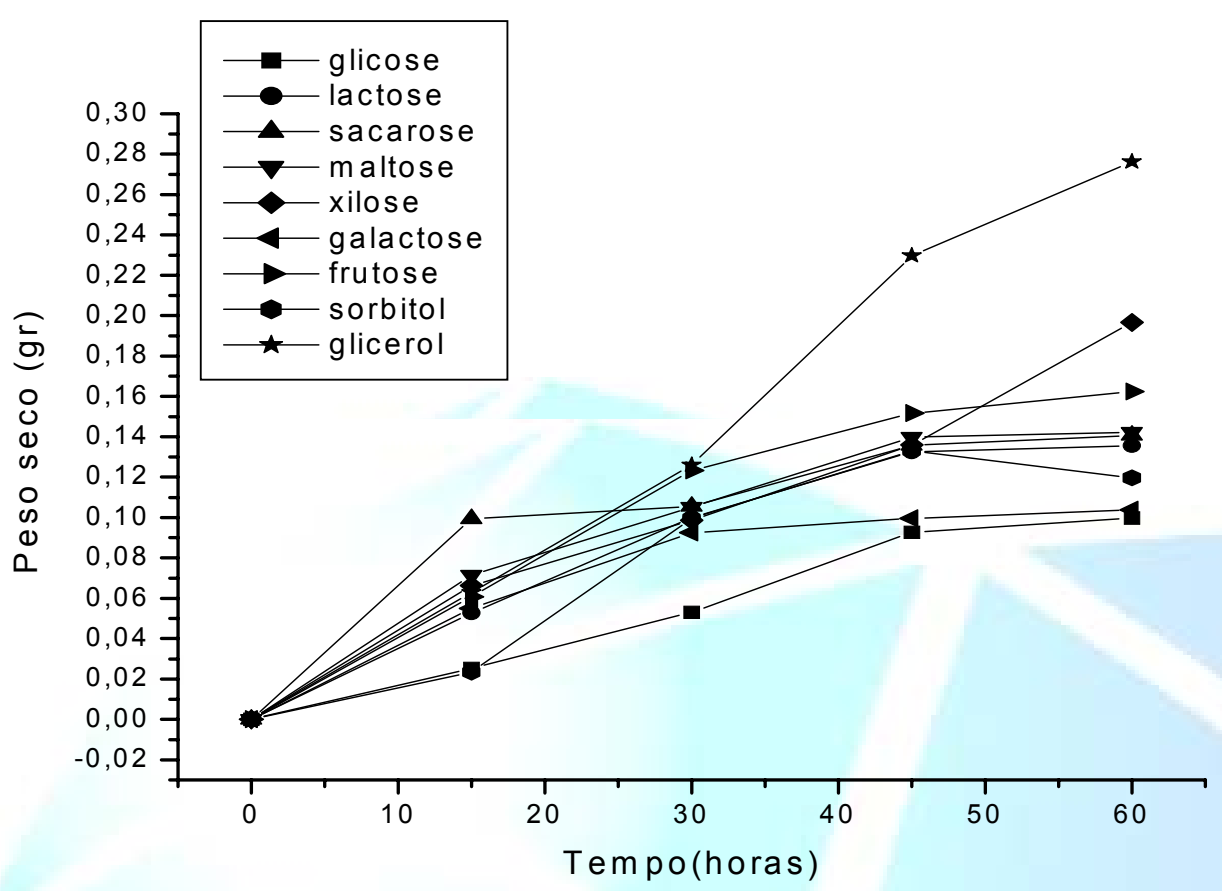

Figura 4- Cultivo de Rhizopus microsporus com diferentes fontes de carbono por método tradicional.

Os resultados obtidos no método tradicional estão de acordo com aqueles citados por Teixeira et al. (2000), estudando os efeitos de fontes de carbono na produção de pectinases por Aspergillus japonicus 586. Fadel (2000) trabalhando com $A$. niger sob condições de fermentação sólida para produção de celulases e glucosidases observou que a suplementação do meio de cultura com maltose, xilose e sacarose aumentou a produção de biomassa, durante o processo de produção enzimática. Meletiadis et al (2001) analisando o crescimento de três fungos filamentosos (Rhizopus microsoporus, Aspergillus fumigatus e Scedosporium prolificans) observaram que $2 \%$ de glicose $(\mathrm{p} / \mathrm{p})$ adicionados ao meio de cultura acarretaram pouco crescimento destes microrganismos, correspondendo aos resultados aqui encontrados. Peixoto et al. (2003), trabalhando com Rhizopus microsporus var. rhizopodiformes para a produção de amilases termoestáveis encontraram aumento na produção de biomassa e de enzimas em meio contendo maltose.

Ramachandran et al. (2004), também utilizando fermentação sólida enriquecida com maltose e lactose na produção de $\alpha$-amilases por $A$. oryzae, observaram aumento na produção da biomassa. Durante a imobilização de Aspergillus sp, Gawande e Kamal (2000) utilizaram as mesmas fontes de carbono aqui estudadas e encontraram aumento na produção da biomassa e de xilanases. 
Horakova et al (2003), em trabalho comparativo do método tradicional e método turbidimétrico automatizado no estudo das características de crescimento de Listeria monocytogenes, concluiu que os dois métodos foram similares, e que o método automatizado utilizou menor quantidade de reagentes e menor tempo de analise.

\section{CONCLUSÃO}

Demonstrou-se a viabilidade na utilização de sistemas automatizados para a determinação dos parâmetros cinéticos para a produção de biomassa ou para outros ensaios de atividade microbiana, uma vez que são compatíveis com os métodos tradicionais e com a literatura, além de demonstrarem redução de gastos de meio de cultura e reagentes.

\section{AGRADECIMENTOS}

Ao Centro de Estudos Ambientais da UNESP, pela concessão dos laboratórios e material de consumo e ao Programa de Pós Graduação em Ciências Biológicas, área Microbiologia Aplicada, UNESP, Campus de Rio Claro, SP.

Ao Instituto de Botânica de São Paulo e a Profa. Dra. Iracema S. Crusius pela identificação dos fungos isolados de solo de área de caatinga.

\section{REFERÊNCIAS}

ALVAREZ-BARRIENTOS, A.; ARROYO, J.; CANTON, R.; NOMBELA, C.; SANCHEZ-PÉREZ, M. Applications of flow cytometry to clinical microbiology. Clinical Microbiology. Revue, Madrid, Spain,v.13, p. 167-195, 2000.

BOCHINI, D.A. Estudos de parâmetros fermentativos para produção de xilanase. 2000. 89 p., Dissertação Mestrado em Biotecnologia, Universidade Estadual Paulista Júlio de Mesquita Filho, Araraquara, SP, 2000.

BONONI, V. L. R. Zigomicetos, Basidiomicetos e Deuteromicetos. In: NOÇÕES BÁSICAS DE TAXONOMIA E APLICAÇÕES BIOTECNOLÓGICAS. São Paulo: Instituto de Botânica, Secretaria de Estado do Meio Ambiente, 1999. p.13- 14.

DRUMOND, M. A.; KIILL, L. H. P.; LIMA, P. C. F.; OLIVEIRA, M. C.; OLIVEIRA, V. R.; ALBUQUERQUE, S. G.;; NASCIMENTO, C .E. S.; CAVALCANTE, J. Estratégias para o uso sustentável da biodiversidade da caatinga. In: SEMINÁRIO PARA AVALIAÇÃO E IDENTIFICAÇÃO DE AÇÕES PRIORITÁRIAS PARA A CONSERVAÇÃO, UTILIZAÇÃO SUSTENTÁVEL E REPARTIÇÃO DE BENEFÍCIOS DA BIODIVERSIDADE DO BIOMA 
CAATINGA, 2000. Petrolina. Anais...Petrolina: UFPE, Conservation International do Brasil, 2000. p.341-346.

FADEL, M. Production physiology of cellulases and alfa-glucosidase enzymes of Aspergillus niger Grown under Solid State Fermentation Conditions. Journal of Biological Sciences, Cairo, Egypt, v.1, n. 5, p. 401- 411, 2000.

GAWANDE, P. V.; KAMAT, M. Y. Production of xylanases by immobilized Aspergillus sp. using lignocellulosic waste. World Journal of Microbiology \& Biotechnology, Munbai, India, v.16, p.111-112, 2000.

HORAKOVA, K.; GREIFOVA, M.; SEEMANNOVA, Z.; GONDOVA, B.; WYATT, G. M. A. Comparison of the traditional method of counting viable cells and a quick microplate method for monitoring the growth characteristics of Listeria monocytogenes. Letters in Applied Microbiology, Cloney, UK, v. 38, p.181-184, 2003.

JOHNSTON, M. D. A simple and rapid test for quality control of liquid media, using the bioscreen microbiological growth analyzer. Journal Microbiologic Methods, UK, v. 32, p.37-43, 1998.

LISOWSKA, K.; PALEXZ, B.; DLUGONSKI, J. Microcalorimetry as a possible tool for phenanthrene toxicity evaluation to eukaryotic cells. Thermochimica Acta, Łódź, Poland, v. 411, p.181-186, 2004.

MATTILA, T.; O'BOYLE, D.; FROST, A. J. The growth of compact and diffuse variants of Staphylococcus aureus in bovine mastitic and normal whey. Microbiology Immunology, Espoo, Finland, p.667- 673, 1988.

MELETIADIS, J.; MEIS, J. F. G. M.; MOUTON, J. W.; VERWEIJ, P. E. Analysis of Growth Characteristics of Filamentous Fungi in Different Nutrient Media. Journal of Clinical Microbiology, The Netherlands, v. 39, n. 2, 478- 484 p., 2001.

PEIXOTO, S. C.; JORGE, E. J. A.; TERENZI, H. Rhizopus microsporus var. rhizopodiformis: a thermotolerant fungus with potential for production of thermostable amylases. International Microbiology, Ribeirão Preto, SP, v. 6, p.269273, 2003.

PELCZAR, M. J.; CHAN, E. C. S.; KRIEG, N. R. Microbiologia - Conceitos e Aplicações. 2.ed., São Paulo, 1996. v.1, p.258-271. 
RAMACHANDRAN, S.; PATEL, S. K.; NANPOTHIRIL, K. M.; CHANDRAN, S.; SZAKACS, G.; SOCCOL, C. R.; PANDEY. A. Alpha Amylase from a Fungal Culture Grown on Oil Cakes and Its Properties. Brazilian Archives of Biology and Technology, Curitiba, PR, v. 47, n. 2, p. 309-317, 2004.

RUEGGER, M. J. S.; TAUK-TORNISIELO, S. M.; PASTORE, G. M. Isolamento de fungos produtores de ácido $\gamma$-linolênico de solo da Estação Ecológica de JuréiaItatins, SP. Revista Ciências Farmacêuticas, São Paulo, v. 23, n. 1, 49-58 p., 2001.

SKOWRONEK, M.; FIEDUREK, J. Optimisation of Inulinase Production by $A$. niger. Food Technology Biotechnology.Lublin, Poland, v. 42, n. 3, p.141-146, 2004.

TEIXEIRA, M. F. S.; FILHO, J. L. L.; DURAN, N. Carbon sources effect on pectinase production from Aspergillus japonicus 586. Brazilian Journal of Microbiology, São Paulo, SP, v. 31, p. 286-290, 2000. 